\title{
Research on the Communication Effect of Augmented Reality Technology in Electronic Publications among Youth-A Case Study of “Augmented Reality Interactive Science Reading"
}

\author{
Yun Zhu, Hui Ye, Shukun Tang \\ The School of Public Affairs of the University of Science and Technology of China, Hefei, China \\ Email: zhuyun89@mail.ustc.edu.cn
}

How to cite this paper: Zhu, Y., Ye, H., \& Tang, S. K. (2017). Research on the Communication Effect of Augmented Reality Technology in Electronic Publications among Youth-A Case Study of "Augmented Reality Interactive Science Reading”. Advances in Applied Sociology, 7, 305-318.

https://doi.org/10.4236/aasoci.2017.78019

Received: July 18, 2017

Accepted: August 12, 2017

Published: August 15, 2017

Copyright $\odot 2017$ by authors and Scientific Research Publishing Inc. This work is licensed under the Creative Commons Attribution International License (CC BY 4.0).

http://creativecommons.org/licenses/by/4.0/ With the continuous development of society, publications also continue to develop (c) (i) Open Access

\begin{abstract}
Based on Technology Acceptance Model (TAM), this paper constructs the augmented reality electronic publication communication effect model (AREPCEM) and analyzes the data among youth. It is found that the first-level index (use and recognition) and second-level indicators (external variables, perceived usefulness, perceived ease of use, satisfaction, dependency) have positive relevance to audience recognition among youth.
\end{abstract}

Keywords

Augmented Reality, Electronic Publications, Communication Effect, Youth

\section{Introduction}

from the development of paper publications to the electronic publication stage. According to the definition, electronic publications are digital information that stored in the computer, so that it can be read and written magnetic media on the document information carrier, also known as machine-readable literature or electronic database, tape, floppy disk and CD-ROM in the form of storage and exchange, entered the computer through the screen display and printed for people to read (Azuma et al., 2001). Regardless of how the electronic publication changes, the youth is most concerned about the correct display of content and reading comfort of these two issues (Dünser et al., 2008). The combination of interactivity 
and immersion is one of the best carriers to achieve the correct display and reading comfort of electronic publications. The difference between augmented reality of electronic publications is that they move from static to dynamic, from reading to experience (Huang et al., 2016), so that youth' needs is greatly satisfied, but also to stimulate the youth's second interest in the development of the audience. According to the relevant literature search and practice, the author believed that augmented reality of electronic publications is an extension of traditional paper publications, referring to the computer technology. The virtual publication of the content mapped to the real world, the real content or the environment and virtual content or the environment is superimposed in real time on the same screen or an electronic publication of the same space. At present, domestic and international enhancement of real electronic publications mainly concentrated in product research (Hwang et al., 2016; Lai et al., 2015) and product effects (Phillips, 1991; Rothenberg, 2000). Dünser et al. (2008) identified all papers which include A Revaluations we reviewed research publications between the years 1993 and 2007 from online databases of selected scientific publishers. Lai et al. (2015) uses the technology with iPad mobile device to display 3D models, 3D animations, video splaying, websites and web server connectivity for children education. The results and evaluation of the project shows the interactive $3 \mathrm{D}$ animation and self-assessment functions significantly support students to improve their learning experience and performance. The software product of this project, from the business perspective, creates a new business marketing dimension in digital publishing and increases the selling profits in the book publication business. Hwang et al. (2016) designed a competitive gaming approach which is proposed to support AR-based learning activities conducted in real-world contexts. An experiment has been conducted on an elementary school ecology course to explore the effectiveness of the proposed approach in comparison with the conventional AR-based mobile learning approach in field trips. The experimental results show that the AR-based gaming approach can improve not only students' learning attitudes, but also their learning performance on the field trip. Accordingly, discussions and some suggestions for future work are provided. Huang et al. (2016) based on Kolb's experiential learning theory, the current study develops an eco-discovery AR-based learning model (EDALM) which is implemented in an eco-discovery AR-based learning system (EDALS). In a field experiment at a botanical garden, 21 middle school students constitute three groups participated in a learning activity using different learning types and media. Quantitative results indicate that, compared to the humanguidance-only model, EDALS successfully stimulates positive emotions and improved learning outcomes among learners. In post-activity interviews, students indicated they found the exploration mode provided by the proposed system to be more interesting and helpful to their learning in school. The use of attractive technologies increases students' willingness not only to learn more about the environment, but also to develop a more positive emotional attachment to it.

Therefore, this paper takes "augmented reality interactive science books" as an 
example, based on the technical acceptance model of AREPCEM to study the future on electronic publications that provide a reference for the spread.

\section{Research Design}

\subsection{Model Design}

Davis (1989) proposed a technology acceptance model (TAM) based on the study of rational behavior theory, which is mainly to study the degree of user acceptance of information systems (Venkatesh \& Davis, 2000). The main contents of the technology acceptance model are: external variables are composed of willingness to use and use attitude, which is determined by the individual's position and perceived usefulness of the system; the attitude towards is shared by perceived usefulness and perceived ease of use. The perceived usefulness of the individual will have a direct impact on the use intention of the individual, and the perceived ease of use will directly affect the perceived usefulness of the individual (Venkatesh \& Davis, 2000). The technology acceptance model considers that the use of the system is determined by the intent of the act, which is determined by the attitudes and perceived usefulness of a person's desire to be used by the usefulness of cognition and the ease of use of cognition. The perceived usability is determined by perceived ease of use and external variables, and perceived ease of use is determined by external variables, while external variables are internal beliefs, attitudes, intentions, and differences in the technology acceptance model of the differences between individuals, environmental constraints, and control of interference between the factors established (Venkatesh \& Davis, 2000).

Figure 1 shows that the technology acceptance model will be "used" into the use of intentions, the use of attitude, perceived usefulness and perceived ease of use in four areas. Therefore, this article to "augmented reality interactive science books" as an example, designed AREPCEM among youth. Which AREPCEM level indicators designed to "use" and "identity" two indicators. The "use" of the secondary index is designed for external variables, perceived usefulness and perceived ease of use. External audiences are used by youth's daily habits, youth's holiday habits, frequency of youth use, and youth use years. Perceived usefulness through the access to relevant news information, youth tend to use which electronic publications, "Recognition" is selected to satisfy (Attitude toward using) and the degree of dependence (Behavioral intention to use and actual system

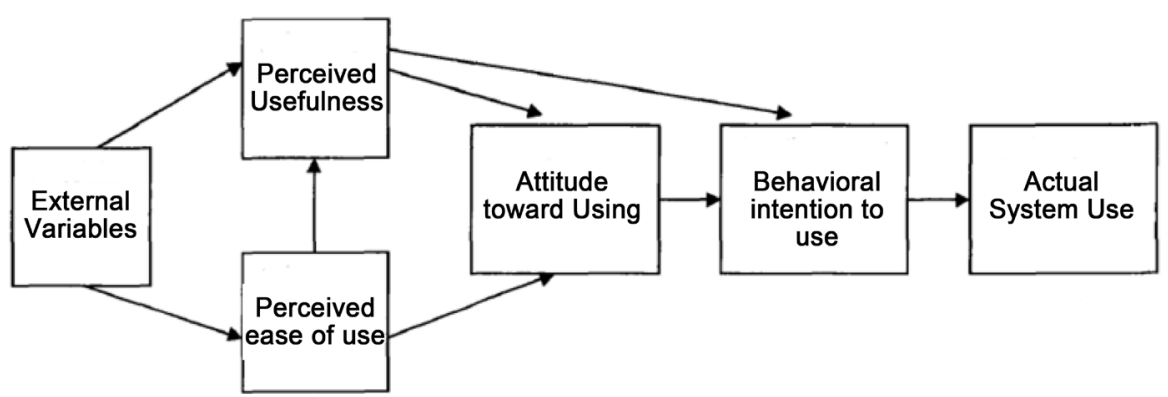

Figure 1. Technical Acceptance Model. 
use) are two indicators of measurement. The degree of satisfaction is measured by a clear presentation, access to knowledge, integration of relevant knowledge context, real-time feedback-related knowledge, multi-sensory integration experience; dependency by youth who have been remembered augmented reality of electronic publications without the use of any electronic publications will recommend other people to measure augmented reality of electronic publications.

Through the above AREPCEM can be speculated that: augmented reality electronic publication among AREPCEM has a positive correlation. Therefore, the author boldly makes the following assumptions:

H1 Augmented reality of electronic publications in the model of the use of factors on the impact of youth has a positive correlation:

H1-1 Augmented reality electronic publication effect model in the external variables will affect the impact of youth spread;

H1-2 Augmented reality electronic publication effect model perceived usefulness can improve the effectiveness of youth communication;

H1-3 The perceived ease of use in the augmented reality electronic publication propagation effect model can improve the effect of youth communication.

$\mathrm{H} 2$ Augmented reality electronic publication in the dissemination of the model of identity factors on the impact of youth has a positive correlation:

H2-1 The satisfaction degree of AREPCEM can improve the effect of the youth.

H2-2 The degree of reliance of AREPCEM can improve the effectiveness of youth.

\subsection{Data Analysis}

\subsubsection{Data Collection}

The author set "augmented reality interactive science books" as an example, from 2017-02-15 to 2017-04-05, selected 350 youths by random in China University of Science and Technology for surveying. A total of 314 valid questionnaires were collected which is about $89.7 \%$ effective.

\subsubsection{Reliability and Validity Analysis}

The usual attitude and opinion questionnaire uses the Cronbach's alpha reliability coefficient, which is used to test the consistency and stability of the topics under the same series of concepts. According to previous studies, Cronbach's $\alpha$ represents the correlation between the subjects under the measurement variables. The larger the Cronbach's $\alpha$ reliability coefficient, the greater the correlation, that is, the higher the degree of internal consistency between the various subjects under the measurement variable.

The author uses SPSS statistical software to test the reliability of each measurement variable of the questionnaire, and accumulate the variance analysis of these measurement variables to check whether the measurement variables of this questionnaire conform to CFA (confirmatory factor analysis). As a result of the augmented reality electronic publication effect of the model of the primary and 
secondary indicators of the measurement factors include different topics, so the author of these items on the total term of the reliability of the further analysis.

Table 1 shows that the measurement factors of the questionnaire and the relationship between the various factors have good reliability, which are suitable for the subsequent validation factor analysis.

\subsubsection{Structural Equation Model Analysis}

1) Confirmatory factor analysis

Based on the above, Figure 2 shows that the model of the validation factor

Table 1. Individuality of the overall reliability analysis table.

\begin{tabular}{|c|c|c|}
\hline Elements & Correlation coefficient & Cronbach's $\alpha$ \\
\hline \multicolumn{3}{|l|}{$\mathrm{X}_{1}$ External variable } \\
\hline $\mathrm{X}_{11}$ Youth daily habits & 0.8143 & \multirow{4}{*}{0.856} \\
\hline $\mathrm{X}_{12}$ Youth holiday habit & 0.7497 & \\
\hline $\mathrm{X}_{13}$ Frequency of youth use frequency & 0.7789 & \\
\hline $\mathrm{X}_{14}$ Youth years of use & 0.7482 & \\
\hline \multicolumn{3}{|l|}{$\mathrm{X}_{2}$ Perceived usefulness } \\
\hline $\mathrm{X}_{21}$ When you get relevant news, youth tend to use the new media & 0.7390 & \multirow{2}{*}{0.776} \\
\hline $\mathrm{X}_{22}$ When leisure and entertainment, youth tend to use what kind of new media & 0.6369 & \\
\hline \multicolumn{3}{|l|}{$\mathrm{X}_{3}$ Perceived ease of use } \\
\hline $\mathrm{X}_{31}$ Youth feel that the new media is better to use & 0.6656 & 0.883 \\
\hline \multicolumn{3}{|l|}{$Y_{1}$ Satisfied } \\
\hline $\mathrm{Y}_{11}$ Clearly show & 0.5472 & \multirow{5}{*}{0.872} \\
\hline $\mathrm{Y}_{12}$ Acquire knowledge & 0.6040 & \\
\hline $\mathrm{Y}_{13}$ Into the relevant knowledge of the situation & 0.6346 & \\
\hline $\mathrm{Y}_{14}$ Real-time feedback related knowledge & 0.6318 & \\
\hline$Y_{15}$ Multi-sensory fusion experience & 0.6994 & \\
\hline \multicolumn{3}{|l|}{$\mathrm{Y}_{2}$ Dependency } \\
\hline$Y_{21}$ Youth have been remembered with knowledge in the absence of their use & 0.6786 & \multirow{2}{*}{0.865} \\
\hline $\mathrm{Y}_{22}$ I will recommend augmented reality electronic publication to others & 0.6786 & \\
\hline
\end{tabular}

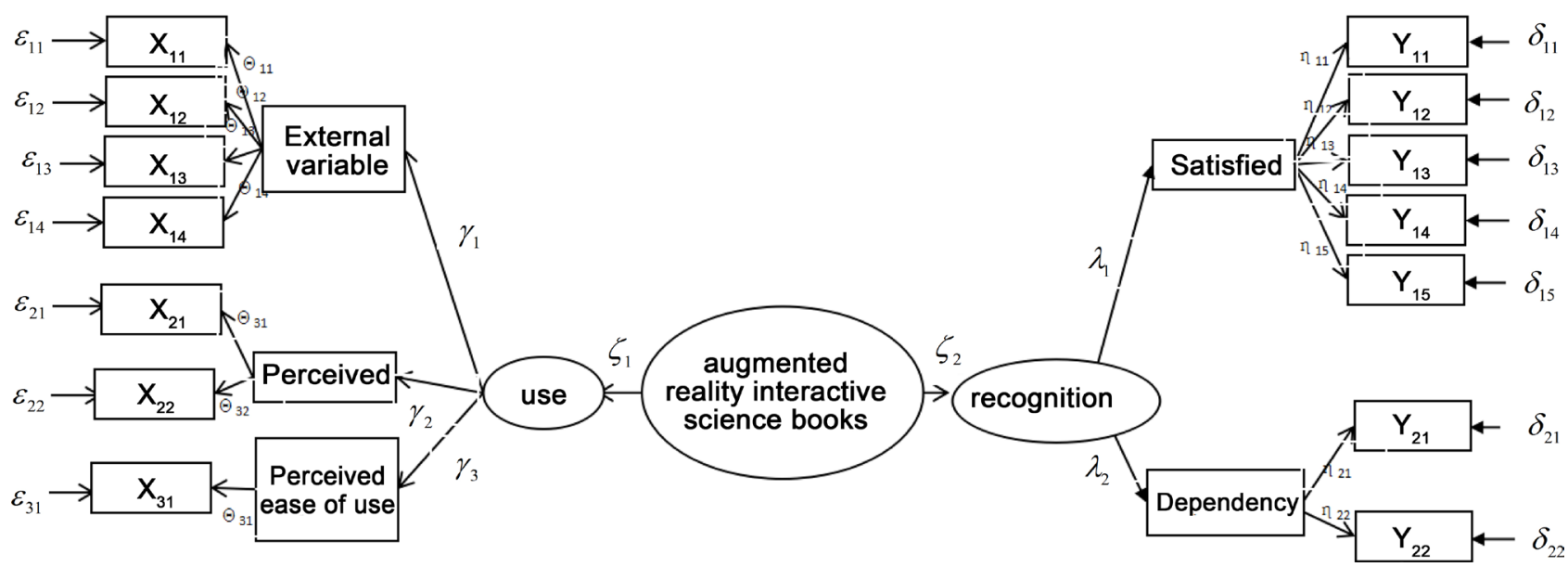

Figure 2. AREPCEM validation factor analysis model. 
analysis model that augmented reality of the electronic publication effect model.

Based on the confirmatory factor analysis model of the augmented reality electronic publications, this paper analyzes the model by LISREL8.70 and obtains the relevant factors and the fitting index.

Table 2 shows that $(Z, \gamma, \lambda, \Theta, \eta)$ are all greater than 0.5 , and the $t$ values of all the observed variables are all greater than 1.96. According to the formula of $t$ value, all the observed variables show a significant level of $t=0.05$. It can be seen that the factors that are included in AREPCEM have good convergence validity.

Table 3 shows that the fitting index of the confirmatory factor and the fitting index of the confirmatory factor were found: $\chi^{2}, \chi^{2} / \mathrm{df}$, RMSEA, NFI, NNFI and CFI are in line with the test standard, which shows that the verification factor of the propagation effect model of the effective in augmented reality electronic publication has good fit.

2) Structural equation analysis

a) Model construction

Through the confirmatory factor analysis of the previous section, the fitting index of the variables in the confirmatory factor model and the relationship between the variables and the observed values is tested and found that the fitting is better. Based on this, the author divided them into five factors to enhance the observed variables of AREPCEM. First, we construct an overall model of AREPCEM. It is expressed as: A means to AREPCEM, $\mathrm{X}$ is used in the model, $\mathrm{X}_{1}$ is the external variable, $X_{2}$ is the perceived usefulness, $X_{3}$ is perceived ease of use; $Y$ is the recognition, where $Y_{1}$ is the satisfaction degree, $Y_{2}$ means the degree of dependence factor. The specific path is presented in Figure 3.

b) Basic fit standard

Table 4 shows that the factor load $(\lambda)$ of each observation variable is more than $0.5, \mathrm{t}$ value is greater than 1.96 ( $\mathrm{t}$ is greater than 0.05 significant level). There are no negative measurement errors in all the factors that the effectiveness in AREPCEM. Therefore, the structural equation model is a good fitting model.

c) Overall fit of the model

According to the generalized exponential index of structural equation model, Table 5 shows that the structural equation model conforms to the global fitting index standard.

d) Intrinsic fit of the model

The author constructs the reliability and average variance extraction analysis and measurement of AREPCEM (A), use (X) and recognition(Y), and then understands the intrinsic fit of the structural equation model.

Due to the requirement of the inherent fitting index of the structural equation model, the reliability of construction is greater than 0.7 and the average variation extraction is greater than 0.5 , so the index of all the index factors meet the requirements. Table 6 shows that the structural equation model which the augmented reality electronic publication has good intrinsic fit. 
Table 2. AREPCEM validation factor parameters.

\begin{tabular}{|c|c|c|c|c|}
\hline Parameter & Nonstandard parameter & Standard error & $\mathrm{t}$ value & Standardized parameters \\
\hline$\zeta_{1}$ & 0.62 & 0.05 & 10.86 & 0.80 \\
\hline$\zeta_{2}$ & 0.65 & 0.06 & 11.48 & 0.86 \\
\hline$\gamma_{1}$ & 0.58 & 0.06 & 11.25 & 0.78 \\
\hline$\gamma_{2}$ & 0.68 & 0.06 & 11.08 & 0.78 \\
\hline$\gamma_{3}$ & 0.57 & 0.05 & 8.75 & 0.63 \\
\hline$\lambda_{1}$ & 0.77 & 0.05 & 15.89 & 0.88 \\
\hline$\lambda_{2}$ & 0.62 & 0.05 & 13.57 & 0.80 \\
\hline$\Theta_{11}$ & 0.63 & 0.06 & 12.45 & 0.81 \\
\hline$\Theta_{12}$ & 0.71 & 0.05 & 13.57 & 0.80 \\
\hline$\Theta_{13}$ & 0.63 & 0.05 & 13.95 & 0.94 \\
\hline$\Theta_{14}$ & 0.72 & 0.06 & 12.92 & 0.89 \\
\hline$\Theta_{21}$ & 0.49 & 0.04 & 11.92 & 0.73 \\
\hline$\Theta_{22}$ & 0.51 & 0.04 & 13.12 & 0.78 \\
\hline$\Theta_{31}$ & 0.63 & 0.06 & 12.63 & 0.81 \\
\hline$\eta_{11}$ & 0.62 & 0.08 & 6.89 & 0.72 \\
\hline$\eta_{12}$ & 0.51 & 0.02 & 7.44 & 0.56 \\
\hline$\eta_{13}$ & 0.57 & 0.02 & 7.89 & 0.57 \\
\hline$\eta_{14}$ & 0.52 & 0.03 & 7.96 & 0.59 \\
\hline$\eta_{15}$ & 0.58 & 0.02 & 5.84 & 0.52 \\
\hline$\eta_{21}$ & 0.55 & 0.05 & 15.46 & 0.86 \\
\hline$\eta_{22}$ & 0.55 & 0.02 & 2.81 & 0.52 \\
\hline$\varepsilon_{11}$ & 0.20 & 0.03 & 7.33 & 0.34 \\
\hline$\varepsilon_{12}$ & 0.13 & 0.02 & 7.51 & 0.35 \\
\hline$\varepsilon_{13}$ & 0.34 & 0.04 & 8.96 & 0.60 \\
\hline$\varepsilon_{14}$ & 0.21 & 0.03 & 8.49 & 0.49 \\
\hline$\varepsilon_{21}$ & 0.27 & 0.03 & 8.26 & 0.35 \\
\hline$\varepsilon_{22}$ & 0.18 & 0.03 & 7.13 & 0.23 \\
\hline$\varepsilon_{31}$ & 0.17 & 0.02 & 8.07 & 0.39 \\
\hline$\delta_{11}$ & 0.31 & 0.05 & 8.02 & 0.40 \\
\hline$\delta_{12}$ & 0.13 & 0.05 & 8.41 & 0.15 \\
\hline$\delta_{13}$ & 0.15 & 0.06 & 8.26 & 0.22 \\
\hline$\delta_{14}$ & 0.11 & 0.05 & 9.39 & 0.16 \\
\hline$\delta_{15}$ & 0.14 & 0.05 & 8.65 & 0.18 \\
\hline$\delta_{21}$ & 0.21 & 0.06 & 9.14 & 0.20 \\
\hline$\delta_{22}$ & 0.16 & 0.05 & 9.56 & 0.28 \\
\hline
\end{tabular}


Table 3. Fit Index.

\begin{tabular}{ccccccc}
\hline \multicolumn{9}{c}{ Fit index } \\
\hline Index & $\chi^{2}$ & $\chi^{2} / \mathrm{df}$ & RMSEA & NFI & NNFI & CFI \\
\hline Fit index & 321.27 & 2.21 & 0.06 & 0.95 & 0.94 & 0.93 \\
Inspection standards & The smaller the better & $<3$ & $<0.1$ & $>0.9$ & $>0.9$ & $>0.9$
\end{tabular}

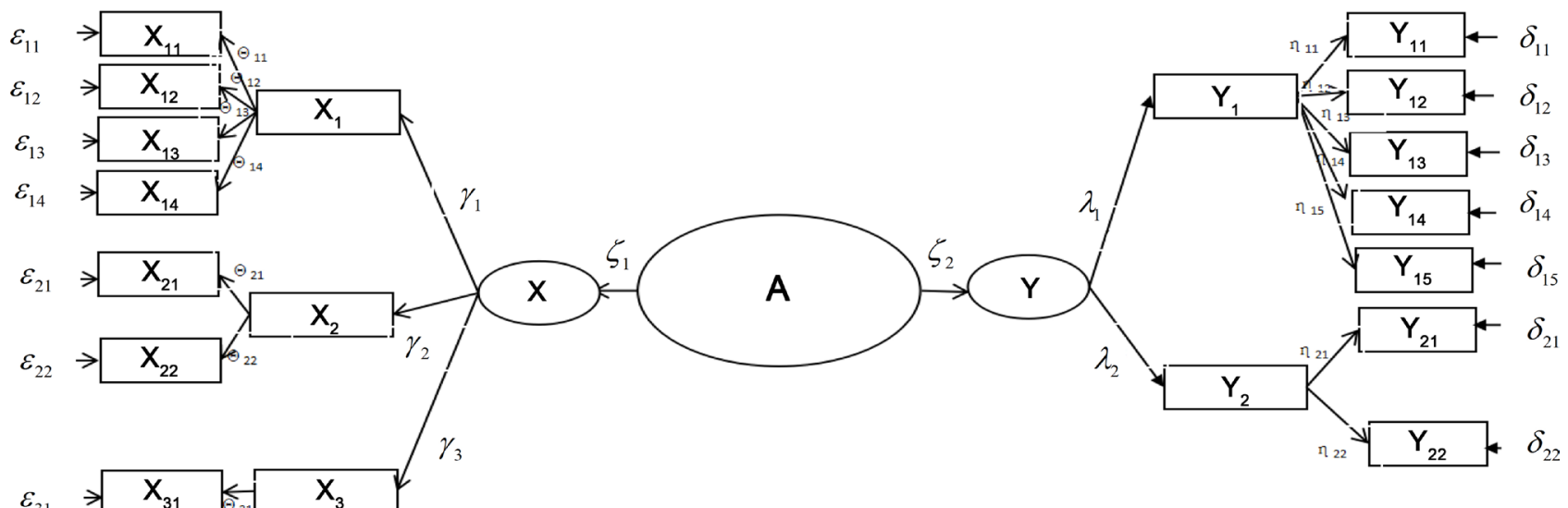

Figure 3. Overall model of AREPCEM.

Table 4. AREPCEM of the factors in the measured variables on the factor load.

\begin{tabular}{cccc}
\hline Observation variables & Index & Standardized parameters & t value \\
\hline \multirow{2}{*}{ AREPCEM (A) } & $\zeta_{1}$ & 0.57 & 5.92 \\
& $\zeta_{2}$ & 0.59 & 8.70 \\
Use $(\mathrm{X})$ & $\mathrm{X}_{1}$ & 0.76 & 13.95 \\
& $\mathrm{X}_{2}$ & 0.83 & 14.61 \\
& $\mathrm{X}_{3}$ & 0.72 & 12.26 \\
$\operatorname{Recognition}(\mathrm{Y})$ & $\mathrm{Y}_{1}$ & 0.87 & 12.89 \\
& $\mathrm{Y}_{2}$ & 0.84 & 12.91 \\
\hline
\end{tabular}

Table 5. Overall fitting index of AREPCEM.

\begin{tabular}{ccccccc}
\hline \multicolumn{7}{c}{ Fit index } \\
\hline Index & $X^{2}$ & $X^{2} / \mathrm{df}$ & RMSEA & NFI & NNFI & CFI \\
\hline Fit index & 63.92 & 2.56 & 0.08 & 0.93 & 0.94 & 0.91 \\
Inspection standards & The smaller the better & $<3$ & $<0.1$ & $>0.9$ & $>0.9$ & $>0.9$ \\
\hline
\end{tabular}

Table 6. Intrinsic fitting index.

\begin{tabular}{ccccc}
\hline Variable & Index & $\mathrm{R}^{2}$ & Construct the reliability & Average variance extraction \\
\hline \multirow{2}{*}{ AREPCEM (A) } & $\zeta_{1}$ & 0.62 & 0.72 & 0.62 \\
& $\zeta_{2}$ & 0.69 & & \\
& $\mathrm{X}_{1}$ & 0.65 & & 0.68 \\
Use $(\mathrm{X})$ & $\mathrm{X}_{2}$ & 0.76 & 0.87 & 0.74 \\
& $\mathrm{X}_{3}$ & 0.73 & & \\
\multirow{2}{*}{ Recognition(Y) } & $\mathrm{Y}_{1}$ & 0.61 & 0.85 & \\
& $\mathrm{Y}_{2}$ & 0.79 & & \\
\hline
\end{tabular}


Table 7. Path parameters.

\begin{tabular}{ccc}
\hline Path & \multicolumn{2}{c}{ Model } \\
\cline { 2 - 3 } & Standardized parameters & t value \\
\hline Use factors $\rightarrow$ youth communication effect & $\zeta_{1}=0.86$ & 11.93 \\
External variable $\rightarrow$ youth communication effect & $\gamma_{1}=0.82$ & 11.58 \\
Perceived usefulness $\rightarrow$ youth communication effect & $\gamma_{2}=0.76$ & 9.51 \\
Perceived ease of use $\rightarrow$ youth communication effect & $\gamma_{3}=0.92$ & 12.99 \\
Recognition factors $\rightarrow$ youth communication effect & $\zeta_{2}=0.90$ & 16.93 \\
Satisfied $\rightarrow$ youth communication effect & $\lambda_{1}=0.89$ & 16.57 \\
Dependency $\rightarrow$ youth communication effect & $\lambda_{2}=0.85$ & 14.21 \\
\hline
\end{tabular}

Table 8. Research hypothesis verification summary.

\begin{tabular}{cl}
\hline Path & Conclusion \\
\hline Use factors $\rightarrow$ youth communication effect & stand by \\
External variable $\rightarrow$ youth communication effect & stand by \\
Perceived usefulness $\rightarrow$ youth communication effect & stand by \\
Perceived ease of use $\rightarrow$ youth communication effect & stand by \\
Recognition factors $\rightarrow$ youth communication effect & stand by \\
Satisfied $\rightarrow$ youth communication effect & stand by \\
Dependency $\rightarrow$ youth communication effect & stand by \\
\hline
\end{tabular}

\section{e) Hypothesis test}

Table 7 shows that the normalized parameters of each independent variable (external variable, perceived usefulness, perceived ease of use, satisfied degree, dependency degree) and the recognition variable (youth communication effect) are all greater than 0 , and the $\mathrm{t}$ value is greater than $1.96 \mathrm{~T}$ is greater than 0.05 ), indicating that the relationship between the independent variables and the dependent variables are in line with the hypothesis test, that is: in the augmented reality electronic publication, there are positive correlations between external variables and youth communication effect. Perceived usefulness is positively correlated with the effect of youth communication. The perceived ease of use has positive correlation with the effect of youth communication. There is a positive correlation between the degree of satisfaction and youth communication effects. The degree of dependence has a positive correlation with youth communication effects.

In this paper, Table 8 shows that the hypothesis is tested by the three main analytical methods, such as descriptive statistical analysis of sample data, reliability and validity analysis and structural equation model analysis (confirmatory factor analysis and structural equation analysis).

\section{Result}

\subsection{Use}

\subsubsection{External Variables}

According to the definition of external variables in the TAM, external variables 
are made up of the intention to use and attitude towards using, which is determined by the individual's perceived ease of use and perceived usefulness of the system; the attitude towards is determined by perceived usefulness and perception ease of use. Thus, the author's external variable that enhances AREPCEM is a combination of basic habits, emotions, and cognitive behavior, through the corresponding carriers and channels for youth to create such as contact behavior and the two-way interaction between the publication and other experience, and then show the youth self-awareness and values of a degree of recognition of the means of action.

According to the author's model, external variables are measured by the youth's daily habits, youth's holiday habits, youth use frequency, youth years of use. As we all know, external variables are not only the requirements of the youth itself, but also the environment where the experience there is a certain requirement. And AREPCEM of the surrounding environment creates the environment, real-time interaction so that youth not only get knowledge, but also based on their own habits of interest, even are stimulated by the power to get. At the same time, the author in the above assumptions H1-1: augmented reality electronic publication effect model in the external variables will affect the impact of youth spread. According to the above data analysis, in AREPCEM, external variable path parameters are high, that is, the model in the external variables will affect the impact of youth to disseminate the effect.

\subsubsection{Perceived Usefulness}

According to TAM, the perceived usefulness will have a direct impact on the willingness of the individual to use, in addition to having an impact on the use attitude. Therefore, the AREPCEM proposed by the author perceived usefulness refers to the ease with which youth use to enhance practical skills. Perceived usefulness will be affected by external variables, such as the use of youth habits, the use of behavior and so on.

Based on AREPCEM, perceived usefulness secondary indicators through access to relevant news information, youth tend to use what kind of new media, leisure and entertainment, youth tend to use which new media of these two indicators to study. During the augmented reality electronic publication communication process, media $\rightarrow$ youth, youth $\rightarrow$ youth, youth $\rightarrow$ media communication relationship composed of multiple, as well as the process of choice in different ways of technology, the formation of the dissemination in knowledge rich path. At the same time, in the mass communication era, people have become accustomed to the technical context of the "understanding of their own world is often not from direct observation and personal experience, but relies on others or the mass media to provide the situation". And the augmented reality electronic publication with its convenient, strong sense of experience can let the youth perceived knowledge. For example: the augmented reality electronic publication in the rigid body or fluid simulation experiment combined with the development of the physical engine, so that youth feel like in the real physical environment, by ma- 
nipulating the marker card to simulate rigid body or fluid in the ideal state behavior, access to its physical attribute experience. As the rigid body or fluid can not be in the real physical environment in the ideal state, other graphic media, 3D animation media and so on, this ideal process can only use the language of the text, picture or animation model of these forms or some show forms. Youth in less form of presentation are not easy to integrate their own cognitive habits. As a result, more than $60 \%$ of youth feel inclined to use real-world electronic publications when they get relevant news and entertainment. Meanwhile, the author assumes H1-2: augmented reality electronic publication effect model perceived usefulness can improve the effectiveness of youth communication. According to the above data analysis, in AREPCEM, perceived usefulness path parameters are higher, that is, perceived usefulness has a greater impact on its identity.

\subsubsection{Perceived Ease of Use}

Perceived ease of use in the "TAM" directly affects the perceived usefulness of the individual. Therefore, the author sets AREPCEM. Perceived ease of use refers to the extent to which youth use the effort to augmented reality electronic publications, or to make it easier to enhance the availability of augmented reality electronic publications. Perceived ease of use will directly affect the perceived usefulness of youth.

According to AREPCEM, perceived ease of use through the youth feel that the new media to use this three-level indicators to conduct research. In AREPCEM, youth will focus on such as rigid body or fluid these can not be in the real physical environment in the ideal state of transmission, to achieve their own media and other media differentiation of awareness. Youth sense the sensory experience by sensory knowledge to the augmented reality electronic publication and other types electronic publications to distinguish between the impression in the mind, a variety of sensory experience together, so that knowledge transfers to maximize. More than two-thirds of the youths feel that the augmented reality electronic publication relative to other graphic publication, 3D animation publication and other practical operations and expectations are better for use. For example: the augmented reality electronic publication on the simulation of cell activity shows that the cell structure and changes in the process of display, coupled with the youth real-time interaction, allows youth from different angles to observe the cell activity of a series of scientific processes, and even can independently speed up or extend the scientific process, thereby enhancing the interest in learning. So that youth are in the interactive experience in the relevant knowledge, in the realization of multi-angle cognitive experience at the same time to strengthen the spread effect. Other graphic publication, 3D animation publication and other publication in the structure of the show and process to understand the structure of the cell and its changes in the process of display content are not easy to observe, easy to use. So the augmented reality electronic publication is to use. At the same time, the author in the above hypothesis H1-3: 
the perceived ease of use in the augmented reality electronic publication propagation effect model can improve the effect of youth communication. According to the above data, it is shown that the use of factors to enhance the effectiveness of AREPCEM is the highest, that is, perceived ease of use can improve the spread of youth in AREPCEM.

\subsection{Recognition}

\subsubsection{Satisfied}

TAM shows that the actual system will make use of youth to produce satisfactory results. Therefore, the AREPCEM proposed by the authors must appeal to the satisfaction of the youth. The augmented reality electronic publication and other types of publications are different for its dissemination of knowledge and cultural connotation; knowledge and cultural connotation is an invisible product. Therefore, the degree of satisfied is particularly important in the augmented reality electronic publication among youth. At the same time, poor performance of AREPCEM may result in the youth's dissatisfaction towards certain knowledge. Therefore, the degree of youth's satisfaction is the basis for the ultimate goal of enhancing the effectiveness in the augmented reality electronic publication.

According to AREPCEM, the degree of satisfied through the display, real-time feedback related knowledge, multi-sensory integration experience of the three indicators constitute the test. Youth use real-time interactive experience in the augmented reality electronic publication through the combination of the actual situation with the system, a clear understanding of the need to understand the physical knowledge, and access to different situations, to achieve sensory multi-dimensional experience. For example: the augmented reality electronic publication on the DNA replication of this biological phenomenon simulation, shows the abstract structure of the DNA and its abstraction process of three-dimensional simulation shows that allowing youth immersed in which interactive, more intuitive display, letting youth access to knowledge, into the relevant knowledge of the situation, real-time feedback related knowledge, multi-sensory integration experience, in order to achieve better communication effect. Because the scientific phenomenon of DNA replication is difficult to observe under the microscope, other graphic publication, 3D animation publication and other publication indirect display method, it is difficult for youth to experience, youth can only rely on imagination to be able to form memory in the mind, this abstract memory due to individual differences in individual audience led to different cognitive effects, the difference is greater. Therefore, the augmented reality electronic publication allows youth to acquire knowledge, into the relevant knowledge of the situation, real-time feedback related knowledge, multi-sensory integration experience. At the same time, the author in the above hypothesis $\mathrm{H} 2-1$ : the satisfaction degree of AREPCEM can improve the effect of the youth. According to the data analysis of the above table shows enhances to AREPCEM, the satisfaction degree of path parameters is high, that is, satisfied can improve the effectiveness of youth communication in AREPCEM. 


\subsubsection{Dependency}

"TAM" shows that the degree of dependency on the use of the actual system is an indispensable bridge between youth and media communication. Thus, in AREPCEM, the augmented reality electronic publication through youth relies on the youth to create a positive emotional experience, so that youth are in the promotion of real electronic publications in the communication of consciously or unconsciously to the publication of a certain degree of dependence. The author builds AREPCEM, the degree of dependency is tested by the youth who have been remembered by the use of knowledge and will recommend others in the augmented reality electronic publication. It is well known that the emotional experience of youth is the strongest path in the augmented reality electronic publication. Youth have a strong dependence on emotional experience in the process of interacting in the augmented reality electronic publication, and continue to deepen over time. In the process of youth experience, the direct face of interaction is one of the most powerful emotional dependence, this direct face interaction will continue to stimulate the youth perception of the organ, get a strong dependence experience. Thus, under the same or identical conditions of the carrier, the youth tends to choose products that make themselves feel good and will maintain lasting loyalty and promote in the augmented reality electronic publication.

As a result of the augmented reality electronic publication that youth get the greatest degree of cognitive stimulation and experience, expand the creative thinking, to achieve a more effective dissemination of recognition results. And other graphic publication, 3D animation publication and other publications are usually only able to meet the augmented reality electronic publication to promote the effectiveness, 3D animation publication and other publication can only get a level or a certain level of overlapping interaction rarely. As a result, the effect of the augmented reality electronic publication is higher than that of other publication. At the same time, the author in the above hypothesis H2-2: The degree of reliance of AREPCEM can improve the effectiveness of youth. According to the above table data analysis shows that in AREPCEM, dependency path parameters are higher, that is, dependency can improve the effectiveness of youth.

\section{Conclusion}

The results from our study found that the first-level indicators (use recognition) and secondary indicators (external variables, perceived usefulness, perceived ease of use, satisfied, dependency) have a positive correlation to youth identity. Although the current study has its shortcomings, they can be resolved with future research and much larger collection of data sample. Future data should include variables such as gender, occupation, age, education and other demographic in order to better understand the impact of recognition process factors and factors among youth. 


\section{References}

Azuma, R., Baillot, Y., Behringer, R., Feiner, S., Julier, S., \& MacIntyre, B. (2001). Recent Advances in Augmented Reality. IEEE Computer Graphics and Applications, 21, 3447. https://doi.org/10.1109/38.963459

Davis, F. D. (1989). Perceived Usefulness, Perceived Ease of Use, and User Acceptance of Information Technology. MIS Quarterly, 13, 319-340. http://www.jstor.org/stable/249008

Dünser, A., Grasset, R., \& Billinghurst, M. (2008). A Survey of Evaluation Techniques Used in Augmented Reality Studies. Human Interface Technology Laboratory New Zealand, 1-5.

https://www.researchgate.net/publication/216867631_A_Survey_of_Evaluation_Techni ques_Used_in_Augmented_Reality_Studies

Huang, T. C., Chen, C. C., \& Chou, Y. W. (2016). Animating Eco-Education: To See, Feel, and Discover in an Augmented Reality-Based Experiential Learning Environment. Computers \& Education, 96, 72-82. https://doi.org/10.1016/j.compedu.2016.02.008

Hwang, G. J., Wu, P. H., Chen, C. C., \& Tu, N. T. (2016). Effects of an Augmented Reality-Based Educational Game on Students' Learning Achievements and Attitudes in Real-World Observations. Interactive Learning Environments, 24, 1895-1906. https://doi.org/10.1080/10494820.2015.1057747

Lai, A. S., Wong, C. Y., \& Lo, O. C. (2015). Applying Augmented Reality Technology to Book Publication Business. In e-Business Engineering (ICEBE), 2015 IEEE 12th International Conference, 23-25 October 2015, Beijing, 281-286.

http://ieeexplore.ieee.org/abstract/document/7349981/

Phillips, R. L. (1991). MediaView: A General Multimedia Digital Publication System. Communications of the ACM, 34, 74-83. https://doi.org/10.1145/105783.105799

Rothenberg, J. (2000). An Experiment in Using Emulation to Preserve Digital Publications, $1-28$.

https://pdfs.semanticscholar.org/f95e/30933c29f8b1b3b8b51c62343a8b99dc5cac.pdf

Venkatesh, V., \& Davis, F. D. (2000). A Theoretical Extension of the Technology Acceptance Model: Four Longitudinal Field Studies. Management Science, 46, 186-204. https://doi.org/10.1287/mnsc.46.2.186.11926

\section{Submit or recommend next manuscript to SCIRP and we will provide best service for you:}

Accepting pre-submission inquiries through Email, Facebook, LinkedIn, Twitter, etc. A wide selection of journals (inclusive of 9 subjects, more than 200 journals)

Providing 24-hour high-quality service

User-friendly online submission system

Fair and swift peer-review system

Efficient typesetting and proofreading procedure

Display of the result of downloads and visits, as well as the number of cited articles

Maximum dissemination of your research work

Submit your manuscript at: http://papersubmission.scirp.org/

Or contact aasoci@scirp.org 